BULLETIN Bulletin hispanique

HispaniQuE Université Michel de Montaigne Bordeaux

120-1 | 2018

Varia

\title{
Nuevos datos sobre la extraña edición de un manuscrito geográfico de Hernando Colón
}

Du nouveau sur l'étrange édition d'un manuscrit géographique de Fernand Colomb

Something new upon the stange edition of a geographical manuscript by

Fernand Colomb

José Javier Rodríguez Toro

\section{OpenEdition}

\section{Journals}

Edición electrónica

URL: https://journals.openedition.org/bulletinhispanique/5803

DOI: 10.4000/bulletinhispanique.5803

ISSN: 1775-3821

\section{Editor}

Presses universitaires de Bordeaux

\section{Edición impresa}

Fecha de publicación: 30 junio 2018

Paginación: 163-184

ISBN: 979-10-300-0298-0

ISSN: 0007-4640

\section{Referencia electrónica}

José Javier Rodríguez Toro, «Nuevos datos sobre la extraña edición de un manuscrito geográfico de Hernando Colón», Bulletin hispanique [En línea], 120-1 | 2018, Publicado el 01 enero 2022, consultado el 08 enero 2022. URL: http://journals.openedition.org/bulletinhispanique/5803 ; DOI: https://doi.org/ 10.4000/bulletinhispanique.5803 


\title{
Variétés
}

\section{Nuevos datos sobre la extraña edición de un manuscrito geográfico de Hernando Colón}

\author{
José JAVIER Rodríguez TORO \\ Universidad de Sevilla
}

La découverte récente à la Biblioteca Nacional de Madrid de quatre documents dont ce travail livre le contenu, éclaire de manière quasiment définitive les tenants et les aboutissants de l'édition de la Cosmografía de España (ou Itinerario) de Fernand Colomb parrainée par la Real Sociedad Geográfica au début du XX siècle. Tomás Marín (1970) avait prêté peu d'attention à un fait fondamental pour l'étude du manuscrit colombien.

Mots-clés: Hernando Colón, Cosmographie de l'Espagne, édition.

El reciente hallazgo en la Biblioteca Nacional de Madrid de cuatro documentos, cuyo contenido este trabajo da a conocer, aclara de manera casi definitiva los entresijos de la edición de la Descripción y Cosmografía de España (o Itinerario) de Hernando Colón patrocinada por la Real Sociedad Geográfica a principios del siglo XX. Tomás Marín (1970) apenas había prestado atención a un asunto fundamental para el estudio del manuscrito colombino.

Palabras clave: Hernando Colón, Cosmografía de España, edición.

The recent discovery, in the Biblioteca Nacional in Madrid, of four documents, which this work discloses, clarifies almost definitively the intricacies of the publishing of Ferdinand Columbus' 'Descripción y Cosmografia de España' (or 'Itinerario'), which was sponsored by the Real Sociedad Geográfica in the early twentieth century. Not even Tomás Marín's in depth work (1970), managed to pay enough attention to an issue that seems fundamental to the study of the Columbian manuscript.

Keywords: Hernando Colón, Cosmography of Spain, edition. 


\section{INTRODUCCIÓN}

Las signaturas 10-1-2 y 10-1d-3 de la Biblioteca Colombina de Sevilla corresponden a sendos códices conocidos conjuntamente como Itinerario de Don Hernando Colón por España o Descripción y Cosmografía de España (citada desde este punto como Descripción), cuyo contenido nadie podría explicar mejor que el bachiller Juan Pérez, el fiel servidor que se encargó de la famosa Librería al morir en 1539 el menor de los hijos de Cristóbal Colón ${ }^{1}$. En efecto, en la Descripción que «tuvo propósito de hazer» Colón, afirma Pérez, deberían quedar recogidas «todas las particularidades y cosas memorables» del país, «todas las cosas notables que hay en cada pueblo». Teniendo en cuenta el desarrollo experimentado por la cosmografía en la época del Renacimiento ${ }^{2}$, ciencia en la que su señor se consideraba una autoridad, «el provecho [de una obra de estas características] era grande para saber las ecelencias de España pues que no hay generación cristiana que del menor pueblo que tenga que no haya hecho discrición y figura para que el que no ha estado en Roma, Jerusalén, Babilonia, en París o en Envers y así de todas las demás, sepa la manera de su sitio y cuán grande es y pueda dar cuenta y razón de ellos como si hobiese estado en ella y aun por ventura mejor porque las particularidades mejor se veen en dibuxo». Y, claro está, dado que "España o por mejor dezir Castilla ha carecido» de ella, Hernando Colón «quiso tomar este trabajo imenso» aun siendo «costa grande». Lástima que, siempre según Pérez, «la invidia no lo dexó llegar al cabo".

Para su realización, indica Pérez, «fue necesario enviar por todos los pueblos de España a algunas personas que se informasen en cada pueblo de los vezinos que había y de todo lo demás que en él hobiese dino de memoria» y, una vez obtenida la información, esos mismos emisarios debían llevarla a Sevilla

1. Para las palabras de Pérez, recogidas en todos los entrecomillados de la Introducción salvo que se indique lo contrario, la transcripción de su Memoria de las obras y libros de Hernando Colón realizada por Tomas Marín, Obras y libros de Hernando de Colón, Madrid, CSIC, 1970, p. 47-49.

2. Pueden verse, entre otros, Francisco Rico, «El Nuevo Mundo de Nebrija y Colón. Notas sobre la geografía humanística en España y el contexto intelectual del descubrimiento de América», en V. García de la Concha, Nebrija y la introducción del Renacimiento en España: Actas de la III Academia Literaria Renacentista, Salamanca, Universidad, 1981, p. 156-185, Víctor Navarro Brotóns, "La cosmografía en la época de los descubrimientos», en A. Ma Carabias, Las relaciones entre Portugal y Castilla en la época de los Descubrimientos y la Expansión Colonial, Salamanca, Universidad, 1994, p. 195-205 y María Isabel Vicente Maroto, «La revolución cosmográfica a partir de los viajes colombinos», en C. Varela, Congreso Internacional. Cristóbal Colón, 1506-2006. Historia y leyenda, Palos de la Frontera, UNIA-EEHA, 2006, p. 89-112. Es muy ilustrativa, en este sentido, la referencia contemporánea realizada por Fernández de Oviedo: «Fernando Colón, que hoy vive, el cual es virtuoso caballero y, demás de ser de mucha nobleza y afabilidad y dulce conversación, es docto en diversas ciencias, y en especial en cosmografía» (apud Juan Guillén, Historia de las Bibliotecas Capitular y Colombina, Sevilla, Fundación José Manuel Lara, 2006, p. 145). 
"por fee de escribano y de testigos fidedinos». Como resultado del trabajo, se encontraba en la librería hernandina, por un lado, «un libro escrito de mano, de cuarto de pliego, cosido en badana negra y atado" que contenía "la memoria de estas cosas memorables» así como "las fees que de ella[s] se traían [como] testimonios», es decir, el códice 10-1-2 $2^{3}$ de la Colombina. De este primer libro, considerado por Pérez "prototipo o oreginal», se sacaron otros siete volúmenes «de cuarto de pliego, escritos de mano y encuadernados en tablas de madera y en cuero embesado y cosidos los cuadernos con unas correas", libros que «tienen mucho papel blanco», en clara referencia al códice 10-1d-3 de la Colombina, apenas relleno ${ }^{4}$. La información, según Pérez, se dispone en él «por orden alfabética»:

La manera que se ha de tener para hallar lo que quisieren buscar en lo que quedó hecho, es que miren la primera letra de la ciudad que quiere[n] buscar y en su lugar le hallará[n] [...] de manera que si alguno quisiere saber Sevilla qué cosa sea o qué vezinos tenga o qué sitios o qué heredades o, al fin, qué cosas memorables haya en ella, irá a la s y allá hallará por su orden todo lo que de ella quisiere saber, los lugares comarcanos a cuántas leguas están cada uno y por qué caminos o lugares van de unos a otros, con todo lo que más deseare saber 5 .

Pero la empresa no se culminó, tal y como se desprende de la breve declaración de Hernando Colón contenida en un memorial dirigido con otro objeto al emperador Carlos: «con el [...] intento y celo de servir a su Majestad», «entendía en hacer la discrección y cosmografía de España, a que por el Presidente que era del Real Consejo de vuestra Majestad me fue puesto impedimento» ${ }^{6}$. La interrupción de que se queja Colón queda confirmada por un interesante documento hallado casualmente a finales del siglo XIX, una Provisión Real del Consejo de Castilla fechada el 13 de junio de 1523 en que se ordenaba al "corregidor o juez de residençia de la çibdad de Cordova o a vuestro alcalde» que se les retiraran a los emisarios hernandinos los salvoconductos y que se les

3. Marín ha insistido en el carácter facticio de este códice, puesto que los cuadernos de que consta se prepararon y se escribieron independientemente: aunque se refieran al mismo asunto y obedezcan a un mismo plan, parece que nunca se pensó en que acabarían conformando el tomo conservado, como demuestra la existencia de un pequeño desgaje del volumen sevillano en la Biblioteca Nacional de Madrid con la signatura 7855. Este fragmento fue dado a conocer a finales del siglo XIX, como se verá a continuación. Sobre el códice 10-1-2, véase Tomás Marín, op. cit., p. 201-202 y 208. Sobre el manuscrito de la Nacional signatura 7855, ibid., p. 225-226 y 238-239.

4. Ibid., p. 238-240.

5. El folio final del códice 10-1-2 recoge, asimismo, unas instrucciones de Hernando Colón para la confección de este segundo volumen. Su transcripción completa ibid., p. 218-220.

6. Cf. Declaración del derecho que la Real Corona de Castilla tiene a la conquista de las provincias de Persia, Arabia e India e de Calicud e Malaca con todo lo demás que al oriente del Cabo de Buena Esperanza el Rey de Portugal sin título ni derecho alguno tiene usurpadas recogida en «Documentos relativos a las Noticias de D. Hernando Colón», documento no 3 por Eustaquio Fernández de Navarrete, Colección de documentos inéditos para la Historia de España, Madrid, Imprenta de la Viuda de Calero, 1850, t. XVI, p. 383. 
requisara cuanto de los trabajos llevaran consigo ${ }^{7}$. Sobre la citada Provisión Real habrá de volverse a continuación porque su descubrimiento suscitó el interés por la Descripción en ciertos círculos de intelectuales madrileños, interés que, si bien efímero y superficial, se concretó en la única edición con que la obra cuenta hasta hoy.

Como es sabido, el autor del estudio más completo sobre la Descripción es Tomás Marín'. La profundidad de su Obras y libros de Hernando de Colón de 1970 dispensa de la realización de más consideraciones al respecto de la empresa científica de Hernando Colón, puesto que a partir de una crítica exhaustiva del estado de la cuestión (con referencia a todos aquellos autores que en mayor o menor medida habían citado la obra antes que él) ${ }^{9}$, Marín analiza con profundidad los originales desde el punto de vista codicológico y paleográfico ${ }^{10}$, sin descuidar en absoluto su contenido ${ }^{11}$. Ahora bien, con ser un trabajo modélico por su rigor, minucioso hasta la extenuación, no deja de sorprender la poca atención que presta Marín a la edición de la Descripción que la Real Sociedad Geográfica de Madrid patrocinó a principios del siglo XX ${ }^{12}$, proyecto editorial al que se aludió en el párrafo anterior. Este aspecto le debió de parecer accesorio, pero está claro que no lo es, sobre todo con vistas a una edición moderna de la que la Descripción está sin duda necesitada ${ }^{13}$.

Tiene razón Marín en que la edición de la institución madrileña «se presenta en forma un poco extraña» ${ }^{14}$ : los tres volúmenes que la integran se publican en 1908, 1910 y 1915, respectivamente. Además, no figura por ningún lado el nombre de su responsable. El brevísimo prólogo (si puede denominarse así) con que se inicia el tomo primero lo suscribe Antonio Blázquez DelgadoAguilera (a la sazón secretario adjunto de la Real Sociedad Geográfica) ${ }^{15}$, el resumen de dos páginas inserto al final del tomo tercero ni siquiera aparece firmado ${ }^{16} \mathrm{y}$, por último, en setecientas cuarenta y cinco páginas impresas solo hay una única nota al pie, en que se dice que "la mayor parte de la copia de este manuscrito la ha facilitado el distinguido escritor D. Nicolás Tenorio» ${ }^{17}$. Pero precisamente la parquedad de los datos debería haber empujado a Marín

7. Su transcripción en Tomás Marín, op. cit., p. 163, n. 1.

8. Ibid., p. 159-252.

9. Ibid., p. 172-198.

10. Ibid., p. 201-208 y 238-244.

11. Ibid., p. 208-212.

12. Ibid., p. 192-194.

13. José Javier Rodríguez Toro, $L a$ Descripción y Cosmografía de España (o Itinerario) de Hernando Colón. Estudio lingüístico, Sevilla, Secretariado de Publicaciones de la Universidad de Sevilla, 2002. Del mismo autor, «D. Nicolás Tenorio y su transcripción de un texto geográfico del Renacimiento", Il Confronto Letterario, 61, 2014, p. 251-264, donde se ofrece el estado de la cuestión.

14. Ibid., p. 192.

15. Hernando Colón, Descripción y Cosmografía de España por Fernando Colón, Madrid, Imprenta del Patronato de Huérfanos de Administración Militar, 1908-1915, t. I, p. 1-4.

16. Ibid., t. III, p. 65-66.

17. Ibid., t. I, p. 5. 
a indagar en el asunto cuando tan riguroso se muestra en el resto de su estudio (y tan crítico con respecto a los demás autores que se habían acercado antes que él a la Descripción) ${ }^{18}$.

Hay que reconocer, eso sí, que los antecedentes inmediatos (la historia conocida u oficial por decirlo de algún modo) de la edición se puede reconstruir bien a partir de los datos aportados por Marín ${ }^{19}$, pero en absoluto es posible afirmar lo mismo sobre su trasfondo, aspecto este totalmente descuidado hasta la actualidad en que la reciente aparición en la Biblioteca Nacional de Madrid de cuatro documentos muy reveladores obliga a su completa revisión, lo que persigue precisamente el presente trabajo. En el Anexo se ofrece una transcripción de dichos documentos.

\section{Noticias SObre la DESCRIPCIÓN ANTERIORES A 1898}

Entre los antecedentes inmediatos de la edición debe destacarse el descubrimiento de la Real Provisión de 1523 ocurrido en la primavera de $1898^{20}$, acontecimiento de relieve ya mencionado y sobre el que más adelante habrá de volverse. Porque lo cierto es que, antes de dicho año, muy poco se sabía sobre la Descripción: algunas alusiones, como la del mismo Hernando Colón o la de su servidor, el bachiller Juan Pérez, ya recogidas en la Introducción de este trabajo, aparte de la muy breve del historiador sevillano Gonzalo Argote de Molina, quien dice: «[Hernando Colón] escribió de su mano quatro libros donde redujo a lugares comunes toda la variedad de sus libros. Escribió otro [libro] de todos los lugares de Espańa y las distancias de unos a otros ${ }^{21}$. Pero en realidad ninguna de ellas será conocida hasta siglos después, con lo que su relevancia es muy discutible.

Además, se cuenta con las referencias superficiales y erróneas (extrañamente cabría decir por las personas que las hacen) de los bibliotecarios de la Biblioteca Colombina en los siglos XVII y XVIII: Juan de Loaysa, por un lado, y Diego Alejandro de Gálvez y su colaborador Rafael Tabares, por otro. Loaysa afirma lo siguiente sobre el «Itinerario de todo lo que anduvo Colón»:

Hizo una descripción itineraria de las ciudades y lugares que anduvo personalmente por toda la Christiandad describiéndolos de su mano tan por menor cada uno que admira leerlo pues en cada lugar grande o pequeño contó los vecinos, casas, leguas, ríos,

18. No menos crítico se mostró Jos al afirmar que entre los puntos pendientes de la historia de Hernando Colón se cuenta «el de su descripción topográfica de España, cuyos materiales salieron a la luz con pobre cortejo erudito en una edición que se asemeja algo a otras hechas con tanta prisa como despreocupación por ilustrar el texto, ediciones que nos hacen recordar el gesto de quien echase carnaza a las fieras», Emiliano Jos, «En las postrimerías de un centenario colombino poco celebrado", Estudios Geográficos, 2/4, 1941, p. 565.

19. Tomás Marín, op. cit., p. 162-198.

20. Ibid., p. 178.

21. Aparato de la Historia de Sevilla que dexo principiada Gonzalo Argote de Molina, f. 50 (signatura 58-5-41 de la Biblioteca Capitular y Colombina de Sevilla). 
calidad de la tierra y todas las demás propriedades y cosas particulares y memorables de cada uno sin dexar ápice que no note: en que se reconoce la summa curiosidad y trabajo que le costó caminar tanto y escrevirlo al mismo tiempo todo con tanta puntualidad: començó el itinerario por agosto de 1519 y lo acabó por el año 1526 de todo lo qual están oi en la librería 6 tomos escrito todo de letra del mismo Don Fernando, obra de grandíssima traça y indecible prolixidad ${ }^{22}$.

De acuerdo con Marín ${ }^{23}$, Loaysa "fantasea» «en casi todo cuanto dice», escribiendo "muy de memoria», pues "lo que nos dice no es cierto o lo es solo a medias, muy a medias»: la obra solo recoge datos del territorio peninsular, se sabe que Hernando Colón no la hizo en persona (ni la gran mayoría de lo conservado fue escrito por él) y las fechas -ni siquiera la inicial, "lunes III de agosto de 1517 comencé el itinerario», inscrita por Colón en el primer folio manuscrito- tampoco son acertadas.

Gálvez y Tabares, un siglo después, consignaron esta escueta descripción de los códices:

Extant etiam de manu eius quatuor volumina in folio, in quibus curiositates notabiliores ex iis, quas scivit, et in itinere suo vidit, annotavit, omnis penitus eruditionis generis plenas et non parum ad historiam utiles (BB 150-22)

Extat etiam alterum volume in 4 sua et aliorum calamo exaratum, iter eius per Hispaniam continens, cui operam dedit tertia die Augusti anni 1517, ut notula, quae in initio codicis de manu eius extat, ostendit: incipit itineris eius descriptio a Caesaraugusta civitate $(B B 148-27)^{24}$.

Tampoco son, a decir de Marín, enteramente fiables, si bien «no resultan tan ponderativos y fantásticos» como Loaysa. Y aunque Gálvez y Tabares atinaron al separar en su enumeración los dos códices de la Colombina (el 10-1-2 y el 10-1d-3), perdieron la buena oportunidad de relacionarlos entre sí, con la confusión que originaron hasta, como se verá, finales del siglo XIX. Además, el 10-1d-3 fue clasificado bajo el membrete, bastante equívoco, de variae eruditae annotationes.

No obstante, algo comienza a cambiar de manera casi definitiva en 1866: en ese año se publicó el volumen II del Ensayo de una biblioteca española de libros

22. Juan de Loaysa, ABCdario de la Librería de la Santa Iglesia Catedral de Sevilla, p. 3, acabado en 1684 (signatura 57-1-19 de la Biblioteca Capitular y Colombina de Sevilla). Sobre la vida y obras de Loaysa (1633-1709), vid. Juan Guillén, op. cit., p. 245-248. Loaysa fue el archivero y bibliotecario de la Colombina en la segunda mitad del siglo XVII, época en que destacó por «el apoyo que prestó a las obras que se hicieron en la librería y que culminaron en la remodelación de un nuevo local, su preocupación por los fondos, su reubicación y subsiguiente catalogación, así como los testimonios que dejó sobre ella» (ibid., p. 235).

23. Tomás Marín, op. cit., p. 172-173.

24. Diego Alejandro de Gálvez y Rafael Tabares, Índex librorum ómnium qui conservatur in Bibliotheca Sanctae Ecclesiae Patriarchalis Hispalensis, 1783, s.v. Colon Ferdinandus, f. $18 v$ y 19 (signatura B-360/1-2 de la Biblioteca Capitular y Colombina de Sevilla). Gálvez fue el artífice de la recuperación de la Colombina en el siglo XVIII. Era segundo bibliotecario en 1759, primer bibliotecario o bibliotecario mayor en 1763 (una completa semblanza del personaje en Juan Guillén, op. cit., p. 300-303 y 318-323). Para el Índex escrito por Tabares, ibid., p. 325-326. 
raros y curiosos $^{25}$, obra póstuma de Bartolomé José Gallardo, cuya papeleta no 1869 (columnas 512 a 514) se dedica a «Fernando Colón. Descripción de España», en que se recoge la primera descripción material del códice 101-2: «es un grueso tomo en 4 o, manuscrito, de sobre 900 fojas no foliadas, pero numerados los cuadernos, o mejor diré cartapacios, hasta el 46 , que es el último y consta de 27 fojas». Acerca de las manos que intervienen en su redacción, dice Gallardo que «la letra de los primeros cuadernos [es] de Colón», y añade: «los números de los primeros artículos están en cifras literales hasta el 3315», a partir del cual aparecen «con cifras índicas». Merece Gallardo el juicio favorable de Marín dado que «casi todos los datos que aporta el gran bibliófilo son buenos», si bien no acertó a descubrir el códice 10-1d-3 porque habría actuado con prisas, como demuestra que sus transcripciones están plagadas de errores $^{26}$.

Aunque aparentemente sin conexión con la obra de Gallardo, del mismo año 1866 data también la alusión a la Descripción realizada por Cayetano Rosell en la respuesta al discurso de recepción leído el 9 de diciembre, ante la Real Academia de la Historia, por Fermín Caballero. Caballero trató para la ocasión sobre «las noticias descriptivas de pueblos de Castilla, recogidas en la segunda mitad del siglo XVI ${ }^{27}$. En su contestación, Rosell cita como «monumento» bastante anterior a las Relaciones topográficas escritas en tiempo de Felipe II, "otro que se conserva en la célebre Biblioteca Colombina de Sevilla y que en cierto modo pudiera reputarse como bosquejo y preliminar» en referencia al «Itinerario que don Fernando Colón [...] verificó por España, y en parte escribió de su propia mano» ${ }^{28}$. Como dice Marín ${ }^{29}$, "quizá sea esto lo único interesante que sugiere», pues «en todo lo demás anda errado». Y si bien es cierto que para la descripción de los dos códices Rosell se sirve -mediante la traducción al español en el cuerpo del texto y al mismo tiempo transcribiendo para las notas al pie del original en latín- del Índex ya citado de Gálvez y Tabares, el académico no oculta que carece del conocimiento directo del texto original cuando afirma que «no respondemos, sin embargo, de la completa exactitud de nuestro juicio, porque no teniendo estos códices a la vista, solo conservamos de ellos una idea vaga, y la nota de los índices que hemos reproducido» ${ }^{30}$.

25. Madrid, Imprenta y Estereotipia de la M. Rivadeneyra, 1866, p. 512-513.

26. Tomás Marín, op. cit., p. 174.

27. Fermín Caballero, Discurso leído ante la Real Academia de la Historia en la recepción pública del Excmo. Sr. D. Fermin Caballero (9 de diciembre de 1866), Cuenca, Ediciones de la Universidad de Castilla-La Mancha, 1998, p. 8.

28. Ibid., p. 70-71.

29. Tomás Marín, op. cit., p. 175.

30. Fermín Caballero, op. cit., p. 72, n. 1. Marín llama la atención sobre esta ignorancia cuando afirma que "poca autoridad parece podía quedar ya a la explicaciones de Rosell sobre el fin y el método del Itinerario, cuyo conocimiento y noticias, dicho sea de paso, da la impresión que no le eran personales ni directas, sino pasadas muy de mano en mano» (op. cit., p. 175). Pero el caso es que Rosell lo reconoce, por lo que no se entiende la severidad del comentario de Marín. 
Poco posteriores son las obras de Henry Harrisse sobre Hernando Colón ${ }^{31}$. De acuerdo con Marín ${ }^{32}$, quien califica a Harrisse como "precipitado autor», este tiene el mérito de haber sido el primero en tratar de relacionar los dos volúmenes de la Colombina dejando al descubierto con ello el error cometido por Gálvez y Tabares ${ }^{33}$. También es suya la atinada denominación de «diccionario" para el códice 10-1d-3, y todo ello pese a «su típico aire inseguro», pese a "sus inseguridades, equívocos y hasta errores crasos»"

\section{Los antecedentes inMediatos de la edición. Antonio BlÁZQUeZ}

Pero, ¿qué es lo que sucedió en la primavera de 1898 que parece tan trascendental para la edición de la Descripción? En pocas palabras, la obra traspasó entonces los gruesos muros de la Catedral de Sevilla para convertirse en el objeto de interés de los historiadores de la geografía española de la época. El 24 de mayo, el académico Rodolfo del Castillo dio a conocer el documento inédito del año 1523 a que ya se ha hecho referencia, la Provisión Real con que se había prohibido a Colón la continuación de su empresa cosmográfica. Del Castillo dictó ese día una conferencia sobre el tema en la Sociedad Geográfica de Madrid, conferencia repetida el 10 de junio con ligeras variaciones en la Real Academia de la Historia, como puede comprobarse en los respectivos boletines de ambas instituciones científicas ${ }^{35}$.

Pocos meses después, el bibliotecario francés Gabriel Marcel publicó un artículo en Revue Hispanique $e^{36}$ que tenía por asunto los orígenes del mapa de España, trabajo en el que se cita la obra de Hernando Colón gracias al descubrimiento de Rodolfo del Castillo. El trabajo de Marcel, de principios de 1899, es inseparable del escrito por Cesáreo Fernández Duro, que se publicó

31. Juan Guillén, op. cit., p. 527-530, para una semblanza del hispanista estadounidense. Las obras fundamentales son dos, Don Fernando Colón, historiador de su padre. Ensayo crítico, Sevilla, Imprenta y Librería Española y Extranjera de don Rafael Tarascó, 1871, especialmente p. 31, 33 y 48, y Excerpta Colombiniana, París, 1887 (reimpreso por Slatkine Reprints, Ginebra, 1971), p. 264.

32. Tomás Marín, op. cit., p. 175-178.

33. Afirma Harrisse: «El tomo cuarto [de Variae eruditae anotationes de Gálvez y Tabares] es un proyecto de Diccionario geográfico de España, y aún quizá principio de una copia en limpio por orden alfabético de otra obra en cuarto, que es "Descripción itineraria de todas las ciudades y lugares que anduvo personalmente", tal vez por toda Europa. Este volumen abraza solo la Espańa. Es un bosquejo escrito por el secretario de don Fernando, y lleva este encabezamiento: "lunes III de agosto de 1517, comencé el Itinerario"», op. cit., p. 33.

34. Es cierto, no obstante, que en la edición francesa del primero de sus libros, idea luego repetida en la obra de 1887, el citado párrafo cambió a peor al eliminar desde "proyecto de Diccionario" hasta "es un bosquejo escrito por el secretario de don Fernando», op. cit., p. 264.

35. Rodolfo del Castillo, «Documento inédito del siglo XVI referente a D. Fernando Colón», Boletin de la Sociedad Geográfica de Madrid, no XL, 1898, p.193-201, y Boletín de la Real Academia de la Historia, no XXXIII, 1898, p. 114-122.

36. «Les origines de la carte d'Espagne», Revue Hispanique, no 6, 18, 1899, p. 163-193. 
en el Boletín de la Real Academia de la Historia el mismo ańo ${ }^{37}$. Y aunque es verdad que el artículo de Fernández Duro no aporta gran cosa, pues se limita en lo esencial a traducir, a glosar el de Marcel, se le debe a este erudito el descubrimiento de otro importante documento relacionado con la Descripción: el manuscrito 7855 de la Biblioteca Nacional, según Fernández Duro, «fragmento de geografía de España en el siglo XV», "trabajo muy semejante al de don Hernando Colón» ${ }^{38}$, documento que no es otro que el desgaje del códice 10-1-2 tal y como se señaló anteriormente.

Queda claro, en cualquier caso, que el hallazgo de Rodolfo del Castillo se convirtió en un acontecimiento de relieve entre los eruditos madrileńos. Y lo que más interesa destacar: Fernández Duro era secretario perpetuo de la Real Academia de la Historia, pero también presidente de la Sociedad Geográfica de Madrid (o Real Sociedad Geográfica) desde 1900 hasta 1908, los mismos años en los que se gesta la edición de la Descripción, por lo que no es descabellado pensar que el interés de estos intelectuales, interés surgido a partir del descubrimiento del documento de 1523, esté en la raíz de dicha edición. Y para ello, indudablemente, sería imprescindible contar con el original custodiado desde que se redactó en la Biblioteca Colombina de Sevilla.

Antes se ha citado de pasada el nombre de Antonio Blázquez DelgadoAguilera, secretario adjunto de la Real Sociedad Geográfica, como la persona que firmó el breve prólogo que abre el tomo I de la edición. Este mismo autor, en 1904, había publicado el artículo titulado «El Itinerario de don Fernando Colón y las relaciones topográficas», casi simultáneamente en la Revista de Archivos, Bibliotecas y Museos y, "por juzgarle de interés para [sus] lectores», en el Boletín de la Real Sociedad Geográfica ${ }^{39}$. En dicho trabajo, pese a que su conocimiento del original era muy deficiente, se traían a colación todas las aportaciones recientes sobre la Descripción (R. del Castillo, G. Marcel y C. Fernández Duro), pero también las inmediatamente anteriores de F. Caballero y C. Rosell, B. J. Gallardo o H. Harrisse, por lo que, sin riesgo de caer en exageración alguna, puede afirmarse que Blázquez, en aquel momento, era el mayor especialista en la obra. No por casualidad, pues, a partir del número de julio de ese mismo año comienzan en el citado Boletín las veintinueve entregas de «Descripción y Cosmografía de España por D. Fernando Colón (ms. de la Biblioteca Colombina)», artículo de extensión variable que fue dando a conocer hasta abril de 1914 (el Boletín era entonces de periodicidad trimestral) el contenido del primero de los códices conservados en Sevilla ${ }^{40}$.

37. «Los orígenes de la carta o mapa geográfico de España», Boletín de la Real Academia de la Historia, no 35,1899 , p. 502-525.

38. Ibid., p. 515, n. 1.

39. Antonio Blázquez, «El Itinerario de D. Fernando Colón y las relaciones topográficas», Revista de Archivos, Bibliotecas y Museos, $\mathrm{n}^{\circ}$ X, 1904, p. 83-105, y Boletín de la Real Sociedad Geográfica, no XLVI, 1904, p. 103-145.

40. Los datos completos son: Boletin de la Real Sociedad Geográfica, no XLVI, 1904 (julio), p. 325-389; no XLVI, 1904 (octubre), p. 491-538; no XLVII, 1905 (enero), p. 163-176; 
En abril de 1915 apareció de una sola vez «la parte del manuscrito [...] existente en la Biblioteca Nacional de Madrid» (esto es, los fragmentos desgajados del primero de los códices sevillanos con signatura 7855 del que se habló más arriba $)^{41}$.

Marín, dicho sea de paso, nunca reconoció la existencia de esta primera versión por entregas e incluso se permitió criticar a Serrano y Sanz, que sí la menciona en el proemio a su edición de la Historia del Almirante ${ }^{42}$. En opinión de Marín, por el contrario, puesto que se basó en las fechas de la edición en tres tomos, el proyecto de la Real Sociedad Geográfica habría coincidido con la publicación en la Revista de Archivos, Bibliotecas y Museos de un artículo de Simón de la Rosa López, oficial de la Biblioteca Colombina entre 1880 y 1915, «El Itinerario de don Hernando Colón y su Vocabulario Topográfico de España» del año 1906, titulado de manera parecida al de Blázquez ${ }^{43}$. No le falta razón a Marín en considerar a S. de la Rosa como el mejor conocedor de los manuscritos de la obra, como demuestra que sea citado por Rodolfo del Castillo ${ }^{44}$ y Antonio Blázquez ${ }^{45}$ en sus respectivos trabajos, pues, según parece, ninguno de estos dos autores llegaron a conocerlos directamente, pero se equivoca en relacionar su artículo, que fue posterior (y, en cierto sentido, consecuencia o complemento), con la edición auspiciada por la Real Sociedad Geográfica.

no XLVII, 1905 (julio), p. 457-488; no XLVII, 1905 (octubre), p. 515-533; no XLVIII, 1906 (abril), p. 238-268; no XLVIII, 1906 (julio), p. 386-424; no XLVIII, 1906 (octubre), p. 565612; no XLIX, 1907 (enero), p. 113-152; no L, 1908 (enero), p. 85-112; no L, 1908 (julio), p. 391-400; no LI, 1909 (enero), p. 81-128; no LI, 1909 (abril), p. 271-272; no LI, 1909 (octubre), p. 538-540; no LII, 1910 (abril), p. 271-272; no LII, 1910 (julio), p. 338-399; no LII, 1910 (octubre), p. 493-528; no LIII, 1911 (enero), p. 120-128; no LIII, 1911 (abril), p. 233256; no LIII, 1911 (julio), p. 387-392; no LIII, 1911 (octubre), p. 506-516; no LIV, 1912 (enero), p. 126-128; no LIV, 1912 (abril), p. 239-256; no LIV, 1912 (julio), p. 374-384; no LV, 1913 (enero), p. 101-128; no LV, 1913 (abril), p. 260-264; no LV, 1913 (julio), p. 404-408; $n^{\circ}$ LVI, 1914 (enero), p. 105-128; y no LVI, 1914 (abril), p. 355-388.

41. Boletín de la Real Sociedad Geográfica, no LVII, 1915 (abril), p. 147-207.

42. Manuel Serrano y Sanz, Vida y escritos de Don Hernando Colón, Historia del Almirante Don Cristóbal Colón por su hijo Don Hernando, Madrid, Librería General de Victoriano Suárez, 1932, t. I, p. CLI, n. 1. La crítica de Marín, que tan bien conocía el trabajo de Serrano, en Tomás Marín, op. cit., p. 196.

43. Simón de la Rosa López, «El Itinerario de don Hernando Colón y su Vocabulario Topográfico de España", Revista de Archivos, Bibliotecas y Museos, no XV, 1906, p. 106-118 y 260-274.

44. Rodolfo del Castillo, op. cit., p. 200, n. 1: «estos datos son debidos al Sr. Bibliotecario de la Colombina, Don Simón de la Rosa López».

45. Antonio Blázquez, op. cit., p. 105, n. 1, «después de escrito este artículo, recibo atenta carta de D. Simón de la Rosa, de la cual resulta que el cuaderno de la Biblioteca Nacional, escrito en el siglo XV, corresponde a hojas que faltan en el libro de la Colombina [...]». 


\section{Noticias PROCEDENTES DE LA «RESEÑA» Del BOLETÍN}

Ahora bien, como se indicaba más arriba, todo lo anterior vale como la historia oficial de la edición de la Descripción de Hernando Colón. La reconstrucción realizada aclara cuáles son los antecedentes inmediatos y el contexto que propician la edición, pero sigue sin permitir el conocimiento a fondo de los entresijos. De hecho, en papel impreso, solo queda constancia de lo que Antonio Blázquez leyó el 13 de junio de 1905 en la «reseña de las tareas y estado actual de la Real Sociedad Geográfica» con ocasión de la Junta General de dicha institución: así se sabe que en el curso anterior se habían publicado «los primeros pliegos del notable manuscrito de D. Fernando Colón» y que «la donación de la mayor parte de la copia de este voluminoso manuscrito se debe a la generosidad de D. Nicolás Tenorio». Dice Blázquez además que «el Director de la Biblioteca Colombina merece también plácemes por haber autorizado galantemente la continuación de la copia». Prácticamente lo mismo se repite en el breve prólogo al tomo primero: «la Sociedad Geográfica debe al Sr. D. Nicolás Tenorio la atención de haberle facilitado gran parte de la copia del manuscrito, y al Cabildo y personal de la Biblioteca Colombina la autorización y facilidades para copiar el resto»; en la primera página, la única nota de toda la obra (como en la primera entrega del Boletín), dice lo ya sabido: «la mayor parte de la copia de este manuscrito la ha facilitado el distinguido escritor D. Nicolás Tenorio» ${ }^{46}$.

Y aunque el manuscrito colombino se siguió publicando hasta 1915, la referida "reseña» anual se antoja muy parca en noticias al respecto. En la leída en la Junta General de 30 de junio de 1909, solo se apunta que «la Descripción y Cosmografía de España por D. Fernando Colón, sacado de un manuscrito de la Biblioteca Colombina, tiene grandísimo interés histórico» ${ }^{47}$.

En este mismo tomo LI (año 1909), por cierto, se reproduce el discurso de entrada de Antonio Blázquez en la Real Academia de la Historia, discurso titulado "Geografía de España en el siglo XVI $»^{48}$. Como sería de esperar, Blázquez trata de la Descripción, obra que valora como muy destacada entre las de su género. Dicho libro, afirma el nuevo académico, «ha permanecido inédito hasta nuestros días» en que "la Real Sociedad Geográfica [lo] ha empezado a publicar». En la nota al pie no 47 se lee que la Descripción de Fernando Colón, manuscrito de la Biblioteca Colombina en Sevilla, está «en publicación» en el Boletin.

Hay que esperar a la «reseña» presentada el 21 de junio de 1915 para volver a encontrar una referencia de interés. Escribe el secretario adjunto (Luis Tur,

46. Sobre Nicolás Tenorio, vid. infra.

47. Publicado en el Boletín $\mathrm{n}^{\circ}$ LI, octubre de 1909, p. 403, sin que conste el autor.

48. Antonio Blázquez, "Geografía de España en el siglo XVI», Boletín de la Real Sociedad Geográfica, no LI, 1909, p. 186-205. 
desde que en 1907 Blázquez se había convertido en bibliotecario de la Sociedad): «el Sr. Blázquez, nuestro erudito Bibliotecario, con celo plausible, por propia iniciativa y bajo su dirección, ha publicado en tirada aparte el segundo tomo $[\ldots]{ }^{49}$. Debe de tratarse, por error, del tercer tomo. Las noticias, pues, no son solo escuetas, sino ciertamente confusas, con lo que ayudan poco.

\section{Nicolás TENORIO, AUTOR DE LA TRANSCRIPCIÓN}

Los fondos documentales de la Biblioteca Colombina de Sevilla, la institución donde se guardan los textos originales de la Descripción (con la salvedad del pequeño fragmento conservado, bajo la signatura 7855, en la Biblioteca Nacional), aportan un dato fundamental: la identidad de la persona que solicitó permiso para su transcripción, el «distinguido escritor» a quien citaba Antonio Blázquez en la única nota al pie de la edición. En un documento suelto hallado entre los «Papeles no Catalogados» de la Colombina, aún inédito, puede leerse cómo «Don Nicolás Tenorio y Cerero licenciado en Derecho y vecino de esta ciudad a V. I. suplica respetuosamente se le conceda permiso para copiar el manuscrito titulado Itinerario de Don Fernando Colón por España propiedad de la Biblioteca Colombina y Capitular. Sevilla 5 de marzo de 1895». Al margen y con la firma de Servando Arbolí, a la sazón el Bibliotecario Capitular a quien se dirigía la petición, se añade: «facilítese el manuscrito para la copia total solicitada pero con arreglo a lo dispuesto en el Reglamento. 6 de marzo de 1895».

El Reglamento para la Biblioteca de la Santa Iglesia Metropolitana y Patriarcal de Sevilla de $1888^{50}$ contempla, en efecto, que corresponde al Bibliotecario Capitular «dar licencias especiales para leer, copiar, calcar, sacar fotografías o facsímiles en los casos en que se exija autorización» (artículo 5 punto 5). Las condiciones que para copiar un manuscrito de la Colombina habían de cumplirse eran bastante estrictas, como puede comprobarse en el artículo 40 del citado Reglamento:

1. Petición escrita al Sr. Bibliotecario con la firma del interesado, en la que se expresará si se propone leer, tomar notas o copiar total o parcialmente el manuscrito.

2. Que se otorgue la concesión por el Sr. Bibliotecario, la cual deberá recaer en personas de conocida respetabilidad que acrediten o revelen de algún modo interés por el estudio, para evitar que la mera curiosidad o vana ligereza puedan comprometer los intereses del establecimiento.

49. Publicado en el Boletín no LVII, julio de 1915, p. 384 (sin autor). En dicha reseńa se recoge también la intención de Blázquez de «hacer un estudio especial de la Geografía de España, con los índices o tablas que sean convenientes basado en la descripción hecha por D. Fernando Colón», estudio que no llegó a terminarse que se sepa.

50. Catedral de Sevilla, Reglamento para la Biblioteca de la Santa Iglesia Metropolitana y Patriarcal de Sevilla, Sevilla, Imprenta de los señores A. Izquierdo y sobrinos, 1889. 
3. Que en los apuntes o copias no se emplee la tinta sino el lápiz.

4. Que en un libro al efecto llevado se hagan previamente constar el título y autor de la obra, número de folios de que consta, nombre del peticionario y fecha de la concesión.

5. Que a la entrega y devolución del libro se haga por el Oficial el recuento de los folios en presencia del peticionario.

6. Que el asiento se suscriba con la firma y rúbrica del mismo.

7. Que se haga constar en dicho asiento que el Excelentísimo Cabildo se reserva el derecho de propiedad intelectual.

8. Que se designe por el Sr. Bibliotecario el amanuense que haya de verificar la copia.

Pero, además, según el artículo 22 punto 4º debía llevarse un libro con las «licencias otorgadas para la copia de manuscritos o códices de reconocida importancia», el conocido como Libro de asientos en que se anotan las licencias concedidas por el Sr. Bibliotecario Capitular para sacar copias de códices manuscritos de la Biblioteca Capitular y Colombina, en uno de cuyos párrafos reza que «el Señor Bibliotecario Capitular ha autorizado en el día de la fecha al que suscribe para copiar el manuscrito titulado Itinerario de D. Fernando Colón, bajo las condiciones prevenidas en Reglamento. Sevilla 6 de marzo de 1895». Ahora bien, la petición aparece sin firmar, algo que extraña a la vista de la casi totalidad de las solicitudes recogidas en el interesante libro y, en especial, si se tiene en cuenta el apartado 1 del artículo 40 recién transcrito («Petición escrita al Sr. Bibliotecario con la firma del interesado [...]», la cursiva es nuestra). Si Arbolí había autorizado la copia del original, ¿por qué no firmó el solicitante en el Libro?

Llama también la atención la fecha de marzo de 1895 en que se pide permiso para la copia, puesto que es anterior en más de tres ańos a la conferencia de Rodolfo del Castillo, lo que hace pensar en la existencia de un interés independiente del que propició la edición de la Real Sociedad Geográfica. Cabría preguntar qué (o quién) vinculó una iniciativa con la otra, pues es evidente que al final, con el resultado de la edición, se produjo una coincidencia de intereses.

En cualquier caso, ¿quién es Nicolás Tenorio? Para Tomás Marín, el «distinguido escritor» debía de ser un perfecto desconocido según se desprende de sus palabras. Solo gracias a su amigo Francisco Collantes de Terán, archivero del Ayuntamiento de Sevilla, pudo trazar la escueta semblanza recogida en la nota al pie número 70 de su libro: «se trata -resume Marín- de un ilustre magistrado de la Audiencia Territorial de Sevilla, muerto en 1930, cuyas aficiones histórico-literarias [se] plasmaron en varias obras, de relativa amplitud e interés, sobre temas sevillanos, p. e., El Concejo de Sevilla (Sevilla 1901), Noticia histórica de la Real Audiencia de Sevilla (Sevilla 1924), Visitas que D. Enrique III hizo a Sevilla (Sevilla 1924)».

El estudio introductorio de El Concejo de Sevilla escrito por Pérez Carrera y de Bordóns ha completado de manera satisfactoria el brevísimo apunte 
biográfico de Marín ${ }^{51}$. Por él se sabe que Nicolás Tenorio estudió Derecho en la Universidad de Sevilla, carrera de la que se licenció en 1886, que en 1889 ingresó en el Colegio de Abogados y que en 1890 aprobó las oposiciones a juez. Sin embargo, tuvo que esperar diez años para obtener una plaza, período que dedicó al periodismo (fue redactor de El noticiero sevillano y colaboró en El Porvenir) y, en especial, a la investigación histórica en archivos y bibliotecas de la ciudad, a saber, el Archivo de Indias, el Archivo Municipal y la Biblioteca Colombina.

Durante la década final del siglo XIX participó activamente en las tareas del Ateneo Sevillano y Sociedad de Excursiones. No en vano, Tenorio está estrechamente vinculado a la figura de Manuel Sales y Ferré, fundador de esta institución, que había sido profesor suyo en la Universidad. Este intelectual krausista que posteriormente evolucionó hacia una posición científicopositivista, fue catedrático de Geografía Histórica de la Universidad de Sevilla entre 1874 y 1899, año en que se trasladó a la Universidad de Madrid para ocupar la plaza de catedrático de Sociología. En el discurso que leyó con motivo de la inauguración del Ateneo (6 de marzo de 1887) pueden encontrarse las líneas fundamentales de su ideario:

Pueblo que olvida su pasado es pueblo muerto, y, por tanto, el camino para llegar al renacimiento de nuestra patria es despertar la conciencia histórica, hoy adormecida. La Historia nacional tiene por base las Regionales y ésta a su vez, las particulares de los municipios: de aquí la necesidad de registrar en las excursiones, todos los archivos, de observar los usos y costumbres de cada pueblo; de recoger las formas arcaicas del lenguaje, descifrar inscripciones y estudiar monumentos.

Leyendo estas palabras se entiende mejor el interés de Tenorio por la investigación histórica en los archivos. De Sales y Ferré aprendió Tenorio también el respeto al dato, al documento... por eso sus trabajos sobre la Sevilla medieval y del siglo XVI, como demuestra en su obra más conocida El concejo de Sevilla pero también en otras como Las milicias de Sevilla, destacan por los anexos en que transcribía de manera exhaustiva la documentación original. Así pues, no era nada extrańa para Nicolás Tenorio la transcripción de un texto antiguo e inédito como la Descripción de Hernando Colón.

En 1900 fue destinado a la provincia de Orense, donde ejerció como juez de primera instancia hasta 1910: desde 1900 a 1906 en Viana del Bollo y desde 1906 a 1910 en Villamartín de Valdeorras. La ausencia de Sevilla a partir de 1900 determina que la transcripción de la Descripción debió de hacerla con anterioridad a esa fecha (entre 1895 y 1900) y que esta quedó sin completar a tenor de lo que dice Blázquez en la única nota al pie de la edición. Solo faltaría saber cómo llegó su trabajo a la Real Sociedad Geográfica de Madrid produciéndose de este modo la vinculación de dos iniciativas aparentemente

51. Nicolás Tenorio Cerero, El concejo de Sevilla, Sevilla, Servicio de Publicaciones de la Universidad de Sevilla, 1995. Cf. en particular, su apartado «El Ateneo Sevillano y Sociedad de Excursiones. Amigos, investigaciones y trabajos (1887-1900)», p. XXXI-XLIII, porque permite entender bien las coordenadas en que hubo de inscribirse el trabajo de Tenorio. 
independientes en su origen ${ }^{52}$. Según Pérez Carrera y de Bordóns, "Sales y Ferré pudo estar relacionado con la Sociedad Geográfica ya que había sido Catedrático de Geografía, pudiendo haber facilitado a Tenorio la publicación de esta importante obra" ${ }^{53}$.

\section{LOS CUATRO DOCUMENTOS DEFINITIVOS}

El hallazgo en febrero de 2014 de cuatro cartas, bajo la signatura SG Mss Ca 2-39 (C $1885-1904$ ), en el fondo documental de la Real Sociedad Geográfica, fondo depositado desde hace algún tiempo en la Biblioteca Nacional de Madrid, permite conocer algunos de los entresijos de la edición de la Descripción hasta hoy no aclarados ${ }^{54}$.

El documento 1 es sin duda el de mayor interés. Se trata de la carta escrita el 17 de noviembre de 1904 por Simón de la Rosa y dirigida a Antonio Blázquez, como respuesta a una anterior de este cuya existencia se supone. La carta de Simón de la Rosa, la primera cronológicamente de la serie de documentos inéditos que aquí se dan a conocer, acompañaría a un paquete certificado en que de la Rosa devolvía a Blázquez «las pruebas y original del Itinerario de Colón». El trabajo de corrector, pues, le correspondió a de la Rosa que habría vuelto sobre el códice primero de la Colombina (10-1-2) y, según se entiende de sus palabras, fue esta una labor «más penosa de lo que al principio me figuré». Así lo demostrarían las numerosas anotaciones que llenaban los márgenes. Según de la Rosa, que se muestra muy exigente y exhaustivo con el propio trabajo, solo se reproduciría fielmente el original si se hacían constar las abreviaturas (frecuentísimas en el texto original) y se evitaban «no pocas equivocaciones de nombres de lugares y aun de palabras no bien interpretadas».

En vez de encargar a algún "amanuense mercenario» «el cotejo y corrección de pruebas» de la edición con el original, el mismo de la Rosa lo hizo. Esto se nota, sin duda, en la calidad de la transcripción, cuya fidelidad al texto original es digna de encomio. Y ello, aunque reconoce estar muy ocupado, «porque deseaba complacerle». Queda, no obstante, sin aclarar a qué se refiere de la Rosa cuando afirma que «la persona capaz por su competencia de hacer el cotejo y corrección de pruebas es el señor D. José de Valdenebro, a quien según mis noticias, se ha dirigido $\mathrm{V}$. antes de ahora. No conozco otra persona que poderle recomendar»: ¿acaso compartieron el mencionado Valdenebro y él la tarea de corregir las pruebas ${ }^{55}$ ?

52. La cesión le valió a Tenorio su nombramiento, desde 1904, como socio corresponsal de la institución madrileña.

53. Ibid. p. XLV.

54. En el Anexo se ofrece la transcripción íntegra de dichos documentos.

55. Acerca de Valdenebro, puede leerse el reciente trabajo de Juan Montero, "José María de Valdenebro, bibliotecario y benefactor de la Biblioteca de la Universidad de Sevilla», en Eduardo Peñalver (coord.), Fondos y procedencias: Bibliotecas en la Biblioteca de la Universidad de Sevilla: exposición virtual 2013, Sevilla, Secretariado de Publicaciones de la Universidad de Sevilla, 2013, p. 337-349. 
Como ya se ha indicado, el trabajo de Tenorio debió de quedar incompleto por cuanto que Blázquez lo refiere varias veces. La causa de que no terminara la transcripción, como ha quedado dicho, es que fue destinado como juez a Galicia. Aunque en la carta no se recoja referencia cronológica alguna, se sabe que Tenorio abandonó Sevilla en el año 1900. También había llamado la atención que su solicitud de copia apareciera sin firmar. Y, efectivamente, dice de la Rosa: «sucedió que el señor Tenorio fue llamado a ocupar la plaza de juez dejando la copia sin concluir y la licencia por solicitar».

Otro de los puntos no esclarecidos era el de la continuación de la copia al que repetidas veces aludió también Blázquez. La carta de Simón de la Rosa aclara este importante extremo al tiempo que no queda en muy buen lugar (en contraste con la imagen tan positiva que de él proporciona Guillén en su semblanza). Él podría haber gestionado directamente la continuación de la copia, pero conocía bien las reticencias de la Colombina, de manera que recomienda a Blázquez que en nombre de la Sociedad Geográfica (o en el suyo propio) la solicitara, para lo cual debe vencer un obstáculo insalvable según él, la rigidez del reglamento que impediría la copia íntegra de los manuscritos originales que conserva la reconocida biblioteca sevillana: «disponiendo el reglamento de la Biblioteca que no pueden sacarse copias de manuscritos sin licencia del Cabildo eclesiástico, permití a D. Nicolás Tenorio, discípulo mío muy distinguido, que empezara la copia sin perjuicio de llenar el requisito de la autorización más adelante».

Queda así esclarecido por qué la autorización aparece sin firmar en el Libro. También permite saber que Simón de la Rosa está detrás del permiso a Tenorio, identificado este como discípulo suyo.

La estrategia urdida por Simón de la Rosa lo muestra bien: por un lado, utiliza el argumento de que en realidad no se trataría de una copia completa, pues en la Nacional se encontraba (se encuentra) el desgaje como él mismo había demostrado (¿habría viajado a Madrid para comprobarlo cuando apareció? Probablemente sí), pero es que además la Sociedad Geográfica contaba con la parte ejecutada por Tenorio. En segundo lugar, le recomienda que se ofrezca un ejemplar del resultado a la Colombina, algo también recogido por el citado Reglamento. En resumen, de la Rosa sospecha que, con estos dos argumentos, no le quedaría al canónigo director más remedio que acceder a la petición, como así fue finalmente.

El documento 2 de la serie es una copia de la carta enviada por la Sociedad Geográfica, firmada por su presidente, que sigue al pie de la letra las instrucciones de Simón de la Rosa y que Blázquez habría trasladado a Fernández Duro. La carta tiene la fecha de 24 de noviembre de 1904 y está dirigida a José Roca Ponsa, director de la Biblioteca Colombina ${ }^{56}$. En ella se anuncia la intención de

56. Sobre José Roca Ponsa, canónigo magistral entre 1894 y 1938, recoge Guillén, op. cit., p. 554 un detalle que puede explicar las facilidades dadas a la petición de la copia: Roca había propuesto en 1903 la fundación de una revista científica que diera a conocer las riquezas de la 
publicar la Descripción «en beneficio de la cultura general», pero también "para mayor ilustración de la historia de la geografía española».

Como había apuntado Simón de la Rosa en su carta, el obstáculo que podía poner la Colombina era la copia íntegra del manuscrito, frente a lo cual Fernández Duro comienza por recordar que «dos fragmentos [de la Descripción] existen en la Biblioteca Nacional» en referencia al manuscrito 7855 varias veces citado a lo largo de este trabajo. Pero, además, «la Sociedad posee antiguas copias de algunos [fragmentos] de los que se custodian en la Colombina» (es decir, la copia de Tenorio).

En cualquier caso, la Sociedad Geográfica necesitaba completar la copia: «para completar tan interesante documento y darlo íntegro a la imprenta, necesitamos tener copia de lo que nos falta» se lee, lo que solicita por medio de la carta. No se revela la identidad de «la persona a quien encomendemos esta tarea».

Un dato de interés es que en la fecha de la carta ya se habían publicado dos entregas de la edición en el Boletín (los números de julio y octubre), esto es, la Sociedad Geográfica se había lanzado a publicar el manuscrito colombino sin tener asegurada la totalidad de su transcripción. El documento 2 revela también cómo la Sociedad Geográfica había decidido con antelación que la obra acabaría publicada en dos versiones, en el Boletín y «además se tirarán ejemplares aparte», alguno de los cuales se ofrecerá a la Colombina «en su día».

El documento 3 es la respuesta, con sello de la Colombina, del director de esta, José Roca, al presidente de la Sociedad Geográfica, Cesáreo Fernández Duro. Está fechada el 12 de diciembre de 1904. En el párrafo fundamental de la carta, donde se recoge el visto bueno a la petición de copia, afirma Roca que «puede V. hacer presente a esa Real Sociedad de su competentísima presidencia que, hallándome autorizado por el Reglamento de esta Biblioteca para conceder copias parciales de los manuscritos, he sentido viva satisfacción en poder complacerla, quedando por tanto facultada para obtener, por medio del amanuense que a bien tenga designar, copias de los cuadernos del Itinerario de D. Hernando Colón que faltan a la que posee». También agradece «su generoso ofrecimiento a la Biblioteca de donarle un ejemplar de la proyectada edición del Itinerario».

El documento 4, tal vez el menos valioso de la serie, es la copia de la carta que el presidente de la Sociedad Geográfica envió a José Roca. Es una carta sin fecha pero debe de ser de enero de 1905. En ella, Fernández Duro comunica que «en la primera reunión que la Junta Directiva [...] ha celebrado después de las vacaciones de Navidad» dio a conocer la carta de 12 de diciembre de 1904 (el documento 3). La Junta «acordó que constara en acta la profunda gratitud» de la Sociedad Geográfica por haber autorizado la continuación de la copia solicitada.

Colombina, lo que el Cabildo aceptó nombrándolo director. Bien es cierto que «todo se quedó en una ilusión y un consejo de redacción». 


\section{Conclusión}

A la vista de todo lo anterior, en especial de los datos extraídos de los cuatro documentos recién hallados en la Biblioteca Nacional de Madrid, puede afirmarse que no hubo un editor como tal de la Descripción. De hecho la edición de la Real Sociedad Geográfica en cualquiera de sus dos versiones (por entregas o en los tres tomos) se presenta con cierta apariencia de obra anónima. La edición constituiría el resultado de la colaboración, en momentos distintos, de al menos tres personas que muy probablemente no llegaron a tratarse más que por vía epistolar en el tiempo en que esta tuvo lugar. Las tres personas son:

- Antonio Blázquez Delgado-Aguilera, secretario de la Sociedad Geográfica, quien se interesó por la Descripción a raíz del descubrimiento de la Real Provisión de 1523 por parte de Rodolfo del Castillo y entró en contacto con el oficial de la Biblioteca Colombina, Simón de la Rosa López. Gestionó desde su puesto en la Sociedad Geográfica, asesorando a Cesáreo Fernández Duro, la publicación, primero en el Boletín y posteriormente en forma de libros, algo que no fue improvisado sino que estaba previsto desde el principio. Da la impresión, sobre todo por su artículo de 1904, de que Blázquez no llegó a conocer jamás el manuscrito original.

- Nicolás Tenorio Cerero, animado por Simón de la Rosa, quien transcribió parte del original entre 1895 y 1900, fecha en que partió de Sevilla para su destino como juez en Galicia. Su transcripción, aparte de incompleta, no debía de ser muy buena, de ahí que el trabajo de corrector de Simón de la Rosa fuera tan penoso. Hacia finales de 1903 o principios de 1904 cede la copia a la Sociedad Geográfica, se desconoce si por medio de una tercera persona, tal vez el mismo Simón de la Rosa (o Sales y Ferré). La cesión le valió convertirse en socio corresponsal de la institución madrileña.

- Simón de la Rosa López, oficial de la Colombina, fue el mejor conocedor del manuscrito (los códices de la Colombina así como el desgaje de la Nacional), como demuestra su artículo de 1906 y sus aportaciones en los trabajos de Rodolfo del Castillo (que es quien primero entró en contacto con él) y de Antonio Blázquez, con quien hubo de mantener una fluida comunicación. Estuvo detrás de la copia de Tenorio, pues fue quien lo animó a realizarla y posteriormente le correspondió su penosa revisión. Recomendó a Blázquez cómo debía conseguirse la continuación de la copia. A pesar de su destacado papel en todos los trabajos preparatorios de la edición, parece que prefirió quedarse en un segundo plano para no indisponerse con el Cabildo de la Catedral de Sevilla.

Todavía quedan algunos puntos oscuros en la historia de la edición de la Descripción de Hernando Colón promovida por la Real Sociedad Geográfica a principios del siglo XX, por ejemplo, la identidad del copista al que se encargó la parte del manuscrito que Tenorio dejó sin transcribir: ¿el tal José María de Valdenebro citado por de la Rosa en su carta? Tampoco se sabe exactamente 
cómo llegó el trabajo de Tenorio a Madrid: las cartas recién descubiertas revelarían que a principios del año 1904, o incluso antes, ya estaba en poder de Blázquez. ¿Le mandó la transcripción el mismo Tenorio o fue Simón de la Rosa con la aquiescencia de este?

En suma, los documentos que aquí se han dado a conocer suponen un importante avance en el conocimiento de esta destacada iniciativa editorial hasta hace poco apenas intuido.

Anexo

\section{Documento 1}

Sevilla 17 de noviembre de 1904

\section{Sr. D. Antonio Blázquez}

Mi estimado amigo: en paquete certificado envío a V. las pruebas y original del Itinerario de Colón, no habiéndolo hecho antes porque la corrección ha sido, como podrá ver en los márgenes de las páginas, más penosa de lo que al principio me figuré. La reproducción fiel del original exigía hacer constar las abreviaturas y deshacer no pocas equivocaciones de nombres de lugares y aun de palabras no bien interpretadas.

Excuso decirle que no conozco amanuense mercenario capaz de hacer el cotejo con fidelidad y por esta razón y porque deseaba complacerle, tomé a mi cargo el cotejo y corrección de pruebas. A más no me obligo, porque mis ocupaciones no me lo permiten en absoluto.

Debo advertirle, porque el copista no lo ha hecho, que el encuadernador del manuscrito invirtió el orden de las relaciones autógrafas de D. Fernando, colocando las señaladas con los números 416 a 506 antes que las de las cifras 276 a 415, como podrá V. cerciorarse examinando los pliegos siguientes del original. Es indispensable, pues, para que la publicación resulte ordenada, que se componga esta última serie de relaciones antes de dar a luz la anteriormente indicada.

La persona capaz por su competencia de hacer el cotejo y corrección de pruebas es el señor D. José de Valdenebro, a quien según mis noticias, se ha dirigido $\mathrm{V}$. antes de ahora. No conozco otra persona que poderle recomendar.

En cuanto a la continuación de la copia voy a hablarle con la sinceridad que su buena amistad me inspira.

Disponiendo el reglamento de la Biblioteca que no pueden sacarse copias de manuscritos sin licencia del Cabildo eclesiástico, permitía D. Nicolás Tenorio, 
discípulo mío muy distinguido, que empezara la copia sin perjuicio de llenar el requisito de la autorización más adelante.

Sucedió que el señor Tenorio fue llamado a ocupar la plaza de juez dejando la copia sin concluir y la licencia por solicitar.

En evitación de alguna reconvención que me temo, luego que la publicación empiece, y de posibles dificultades que no estarían en mi poder evitar, ¿creería V. prudente dirigirse en nombre de la Real Sociedad Geográfica, o en propio nombre, al Director de la Biblioteca D. José Roca y Ponsa, Canónigo Magistral, haciéndole saber, por medio de carta, que en la Biblioteca Nacional existen dos fragmentos del Itinerario, como así es realmente, y en poder de la Sociedad parte de la copia de los fragmentos conservados en la Colombina, todos los cuales se propone esta publicar en beneficio de la cultura, necesitando para ello que se le permita tomar copia de una parte del códice?

De este modo y ofreciendo a la Biblioteca un ejemplar de los números en que las relaciones se publiquen, estimo, salvo meliori, que conseguiríamos fácilmente llegar al fin sin obstáculos.

El manuscrito no lleva más encabezamiento ni título que el indicado por el señor Tenorio.

No me atreví a darle gracias por el ejemplar de su notable artículo que recibí a su tiempo y agradecí cuanto se merece, porque me anunciaba su ausencia próxima de Madrid.

De V. afmo. amo q. b. s. m.

Simón de la Rosa y López

\section{Documento 2}

Madrid 24 de noviembre de 1904

Sr. D. José Roca y Ponsa, Director de la Biblioteca Colombina de Sevilla

Muy señor mío y de mi más distinguida consideración: Esta Real Sociedad se propone publicar, en beneficio de la cultura general y para mayor ilustración de la historia de la geografía espańola, el llamado Itinerario de Don Fernando Colón, manuscrito que se conserva en esa Biblioteca.

Dos fragmentos de él existen en la Biblioteca Nacional, y la Sociedad posee antiguas copias de algunos de los que se custodian en la Colombina. Mas para completar tan interesante documento y darlo íntegro a la imprenta, necesitamos tener copia de lo que nos falta.

En nombre, pues, de la Corporación que presido me dirijo a V. suplicándole que nos dispense el señalado favor de otorgarnos permiso para que pueda copiar parte del códice la persona a quien encomendemos esta tarea.

La publicación ha de hacerse en el Boletín de esta Sociedad, y además se tirarán ejemplares aparte. Excuso decirle que nos complacerá sobre manera que 
V. se digne aceptar en su día algunos de dichos ejemplares para la Biblioteca que dirige.

Con este motivo, tiene la satisfacción de ofrecerse un muy atento servidor.

q. l. b. 1. m.

El Presidente

\section{Documento 3}

Sevilla 12 de diciembre de 1904

Excmo. Señor D. Cesáreo Fernández Duro, Presidente de la Real Sociedad Geográfica de Madrid.

Muy distinguido Señor mío y de todo mi aprecio: es en mi poder su atenta carta, fecha 23 del pasado, que no he contestado con la puntualidad que mi respetuosa consideración a su persona reclamaba, tanto por haber tenido que consultar algunos precedentes antes de contestarla, como porque, naturalmente, han absorbido casi por completo mis atenciones las suntuosas fiestas religiosas con que Sevilla ha conmemorado el quincuagésimo aniversario de la declaración dogmática de la Inmaculada.

Puede V. hacer presente a esa Real Sociedad de su competentísima presidencia que, hallándome autorizado por el Reglamento de esta Biblioteca para conceder copias parciales de los manuscritos, he sentido viva satisfacción en poder complacerla: quedando por tanto facultada para obtener, por medio del amanuense que a bien tenga designar, copia de los cuadernos del Itinerario de D. Hernando Colón que faltan a la que posee.

Réstame felicitarla cumplidamente por la obra de cultura que se propone realizar y enviarle a la vez, en nombre de este Excmo. e Ilmo. Cabildo Eclesiástico, la expresión sincera de mi más profunda gratitud por su generoso ofrecimiento a la Biblioteca, de donarle un ejemplar de la proyectada edición del Itinerario.

Celebro la ocasión de poder ofrecerme por su atento y S.S. y Cap.

El Bibliotecario

José Roca y Ponsa

\section{Documento 4}

Excmo. Sr. D. José Roca

Bibliotecario de la Capitular Colombina

Muy distinguido señor mío y de mi mayor aprecio: en la primera sesión que la Junta Directiva de esta Sociedad ha celebrado, después de las vacaciones de 
Navidad, tuve el gusto de dar cuenta de la atenta y gratísima carta de V., fecha de 12 de diciembre.

La Junta, muy complacida por la autorización que se sirve concedernos, y no menos, ciertamente, por el agrado con que V. acoge nuestro propósito, y que nos vale su preciada felicitación, acordó que constara en acta la profunda gratitud que a V. debe la Corporación.

Transmito a V. este voto de gracias de la Sociedad y tengo la satisfacción de reiterarme

Su muy atento servidor

q. l. b. l. m.

El Presidente 